Specification of the Technology for Neoclassical Investment Theory: Testing the Adjustment Costs Approach

Author(s): Marzio Galeotti

Source: The Review of Economics and Statistics, Vol. 72, No. 3 (Aug., 1990), pp. 471-480

Published by: The MIT Press

Stable URL: https://www.jstor.org/stable/2109355

Accessed: 08-01-2020 14:10 UTC

JSTOR is a not-for-profit service that helps scholars, researchers, and students discover, use, and build upon a wide range of content in a trusted digital archive. We use information technology and tools to increase productivity and facilitate new forms of scholarship. For more information about JSTOR, please contact support@jstor.org.

Your use of the JSTOR archive indicates your acceptance of the Terms \& Conditions of Use, available at https://about.jstor.org/terms

The MIT Press is collaborating with JSTOR to digitize, preserve and extend access to The Review of Economics and Statistics 


\title{
SPECIFICATION OF THE TECHNOLOGY FOR NEOCLASSICAL INVESTMENT THEORY: TESTING THE ADJUSTMENT COSTS APPROACH
}

\author{
Marzio Galeotti*
}

\begin{abstract}
The paper provides an empirical investigation into the nature of adjustment costs and their implications for modelling the investment process. In particular, their role in today's most popular models of investment, the rational flexible accelerator and Tobin's $q$, is considered. In the analysis it is assumed that costs of adjusting the level of quasi-fixed inputs affect the firm's operations independently of specific optimal decision rules for investment. The results show that the pattern of adjustment costs is consistent with the solution of the optimization problem faced by the firm. However, such structure is more complex than what is usually postulated in the literature. Finally, costs of adjustment represent a significant portion of the unit cost of new capital goods.
\end{abstract}

\section{Introduction}

In truth, the adjustment cost model rests on a very weak empirical foundation. The fact that investment seems to respond to prices with a distributed lag has been alleged to support the adjustment cost hypothesis, but this is a very indirect form of evidence. If it is indeed true that the rate of investment is an argument in firms' production functions, this ought to be directly discernible from data on inputs and outputs (Locke Anderson, 1974, p. 367).

O URRENT neoclassical models of investment stem from the solution of choice-theoretic problems where the firm maximizes the present value of its net after tax cash flow and incurs increasing costs of adjusting the level of its quasi-fixed inputs.

Costs of adjustment (hereafter ADC) are central to this literature. Historically, the idea of ADC was introduced by Eisner and Strotz (1963) to make Jorgenson's analysis fully dynamic. As shown by Treadway (1969), such development has led to the "rational" flexible accelerator, in which the crucial feature is an endogenous speed of adjustment, dependent on the parameters charac-

Received for publication May 23, 1988. Revision accepted for publication October 24, 1989.

* University of Brescia.

I am indebted to Mark Schankerman for his support and advice and to $M$. Ishaq Nadiri for useful comments. I also acknowledge the helpful suggestions and opinions of two anonymous referees. The responsibility for errors is solely mine.

Copyright (C) 1990 terizing the firm's technology. At the same time, Abel (1979) exploited the ADC notion to provide Tobin's " $q$ " theory of investment with solid analytical foundations: that is, the $q$ model can be seen as stemming from the same aforementioned choice-theoretic framework.

Nevertheless, the question of whether ADC actually characterize production technologies has not been addressed empirically in the literature, but only postulated in the formulation and estimation of investment models. Current empirical work on investment and dynamic factor demand theory invariably maintains that ADC are "wellbehaved": that is, they subtract resources from current output production and increase more than proportionately relative to the rate of investment. In addition, some simplifying assumptions are frequently made about their structure (e.g., Berndt, Fuss and Waverman (BFW), 1980).

This paper represents an empirical investigation of ADC taking a different lead. The problem with ADC is that they are essentially unobservable directly even when working with firm-level data. Econometric evidence on ADC has been so far obtained from estimation of investment equations. In this paper we try to infer characteristics of ADC directly from estimation of the firm's technology-cum-ADC. In this process, the role that ADC play in today's most popular models of investment-rational flexible accelerator and neoclassical formulation of Tobin's $q$ theory-is considered. For such investment models to be consistent with the dynamic optimum problem they stem from, ADC must exhibit properties consistent with the solution of that problem. Note, however, that the converse is not true: costs of adjusting quasi-fixed factors may affect the firm's operations regardless of specific optimal decision rules for investment. Thus, unlike previous empirical work making use of the ADC notion, the present investigation provides empirical results and tests that are not conditional on a specific theory of optimal investment behavior. 
The empirical evidence presented here is necessarily imperfect and exploratory, as it does not rest on direct measurement of costs of adjustment. Nevertheless, the methodology we propose makes some progress towards a better understanding of the way ADC are presumed to work.

In the empirical analysis all that is required is the assumption that the firm is in temporary equilibrium and that short-run profits are affected by both the stock and the rate of change of the firm's quasi-fixed inputs. A sufficient estimation framework for this purpose is thus a model belonging to the class that has been termed "second generation dynamics" by Berndt, Morrison and Campbell Watkins (1981). As should become clear later, its alleged drawbacks turn out to be its virtues in this context.

The paper is organized as follows. In the next section we briefly outline the framework and the analytical facts that will be relevant for the empirical investigation. Section III presents the empirical model and the econometric implementation. The results are put forth in section IV. Some $\mathrm{ADC}$ indicators and remarks about empirical investment equations are presented in section $\mathrm{V}$. Brief conclusions close the paper.

\section{The Analytical Framework}

The starting point for the modern neoclassical theory of investment is the intertemporal optimization problem faced by the representative firm aiming to maximize its present net worth. ${ }^{1}$ Assuming price-taking behavior and one quasi-fixed factor, the firm's net after tax cash flow incorporating $\mathrm{ADC}$ is ${ }^{2}$

$$
\begin{aligned}
R= & (1-\tau) \Pi(w, K, \Delta K, t) \\
& -g(1-\eta)[I+c(I)]
\end{aligned}
$$

where $\Pi($.$) is the firm's normalized restricted$ profit function (Lau, 1978), $K$ is the stock of the quasi-fixed input whose net and gross rates of change are related through the usual formula $I=\Delta K+\delta K, \delta$ is the depreciation rate, $(w, g)$ are the prices of the variable input and of the

\footnotetext{
${ }^{1} \mathrm{~A}$ frequent alternative adopted in dynamic factor demand studies is the minimization of the present value of the firm's total costs (e.g., BFW, 1980). We don't pursue this possibility here as Tobin's $q$ theory is formulated in terms of profit maximizing behavior: the market value of the firm is the market capitalization of the firm's profits.

${ }^{2}$ Time subscripts are omitted for simplicity.
}

investment good normalized by the output price, and $(\tau, \eta)$ are, respectively, the corporate income tax rate and the sum of investment tax credit and present value of depreciation allowances on a dollar of new investment (see, e.g., Hayashi, 1982). Finally, the argument $t$ of the profit function is an index of technical progress.

The literature distinguishes between technological and market sources of ADC: these give rise to internal and external costs, ${ }^{3}$ represented in (1) by the $\Delta K$ argument in the firm's profit function and by the unit cost function $c(I)$, respectively. Throughout this paper we will be concerned with internal ADC only. ${ }^{4}$ The reason is that, while for external ADC the negative impact of investment on current output has to be postulated a priori, in the internal case it can be empirically assessed. Also note that, unlike the external case, for the internal case it is possible to study the interaction between ADC and the levels of the variable and other production inputs. Finally, the relationship between $\mathrm{ADC}$ and other technological features (namely, the degree of returns to scale) and their consequences for investment modelling can be analyzed. We will therefore assume $c(I)=0$.

In the literature ADC are taken to depend on either gross or net investment. From a strictly economic point of view the difference is likely not to be irrelevant. Note however that, since gross investment can in general be written as $I=H(\Delta K, K)$, a profit function like $\Pi=$ $P(w, K, I, t)$ can always be redefined as $\Pi(w, K, \Delta K, t)$. For this reason, internal $\mathrm{ADC}$ will be specified here to depend on net investment.

Inclusion of the investment argument in the firm's technology means that adding to a quasifixed factor amounts to giving up some of the available resources used to produce current output in order to expand actual capacity and be able to produce more in the future. Therefore the "marginal productivity of investment" (marginal ADC hereafter) should be negative, since it accounts for the marginal output loss. In addition, on the grounds that it is more costly to do things quickly rather than slowly, it is usually postulated that ADC increase at a faster pace than invest-

\footnotetext{
${ }^{3}$ See Soderstrom (1976) for a thorough discussion.

${ }^{4}$ It must be noted that Tobin's $q$ models are usually based on external-rather than internal-ADC (e.g., Hayashi, 1982). For formulations of the $q$ model based on internal ADC, however, see Hayashi (1985) and Chirinko (1987).
} 
ment: this fact implies that the ADC technology ought to be strictly concave in net investment. Thus, $\Pi_{3}<0$ and $\Pi_{33}<0$ in terms of (1). This requirement has been challenged (Rothschild, 1971). Aside from the reasonableness of such an assumption, what matters for the present purposes is to note that only strictly concave ADC give rise to smooth investment functions and rationalize the observed slow adjustment of quasifixed factors toward their desired level. This crucial regularity condition is statistically tested in section IV.

Unlike the external case, when ADC are incorporated into the firm's technology, interactions are permitted among input levels and their (own and cross) rates of change. This type of interrelation has often been partly or totally ruled out in the literature. Separability of ADC and its degree bear some consequences for investment modelling.

Given the general nonseparable specification in (1), to assume that marginal ADC are not affected by the quantity of variable inputs is equivalent to imposing weak separability. That is, $\Pi_{13}=$ $\Pi_{31}=0$. If one further postulates that costs of adjusting the level of quasi-fixed factors do not even depend on their own quantities, ADC strong separability is assumed: that is, it is assumed that $\Pi_{13}=\Pi_{33}=\Pi_{31}=\Pi_{32}=0$. Installation of capital goods and current output production are in this case completely independent activities within the firm's technology.

Finally, it is commonly held that marginal ADC are zero when the quasi-fixed factors are at their steady-state level: that is, when net investment is zero. Formally: $\Pi_{3}(w, K, 0, t)=0$. This fact ensures that $\mathrm{ADC}$ are at their minimum when $\Delta K$ $=0$ (e.g., BFW, 1980). While reasonable, this assumption turns out to be stronger than strict ADC separability. These separability restrictions will be subject to statistical test in section IV.

What kind of implications does the presumed pattern of ADC just described have for our competing formulations of the optimal investment process?

Both the $q$ model and the rational flexible accelerator are based on the assumption of a value-maximizing firm in a competitive environment. The firm's value is the present discounted stream of future cash flows given in (1). As is well known, optimality requires the firm to equate (the negative of) marginal ADC to the real shadow price of investment. This last variable is related to Tobin's marginal $q$ and is equal to the present value of all future marginal profits obtained from a unit of undepreciated capital. That is,

$$
-\Pi_{3}(w, K, \Delta K, t)=q^{M}
$$

where Tobin's marginal $q$ after taxes is given by $q^{M}=(1-\tau)^{-1}[\lambda-g(1-\eta)]$ and $\lambda$ is the shadow price of investment. Notice, in addition, that the so-called Legendre condition for optimality requires $\Pi_{33} \leq 0$. Hence, technologies that are convex in investment, discussed by Rothschild (1971) and Soderstrom (1976), are explicitly ruled out by the dynamic optimization problem.

Tobin's $q$ model of investment is immediately obtained by solving (2) for $\Delta K$ :

$$
\Delta K=f\left(q^{M}, K, w, t\right)
$$

Notice that the condition $\Pi_{33}<0$, required for optimality, guarantees that investment is an increasing function of $q$ : if $\Pi_{33}=0$, the implicit function theorem could not be applied to invert (2) and no investment function would be defined. ${ }^{5}$ We can therefore conclude that the Legendre optimality condition and the implicit function theorem jointly require the technology to be strictly concave in investment for the $q$ model to emerge. We also note that if ADC are weakly separable (i.e., $\Pi_{31}=0$ ), investment will not be directly affected by variable input prices; if ADC are strongly separable (i.e. $\Pi_{31}=\Pi_{32}=0$ ), investment will also be independent of the capital stock as a separate argument of the functional relationship.

The problem with the $q$ model seen above is that it is not operational as marginal $q$ is unobservable. Nevertheless, Hayashi (1982) has proved the important result that if the firm's technology is linear homogeneous in investment and capital stock, then marginal and average $q$ coincide. Under linear homogeneity, the firm's profit function in (1) becomes (see Diewert, 1986): ${ }^{6}$

$$
\Pi(w, K, \Delta K, t)=K \cdot \rho(w, \Delta K / K, t)
$$

\footnotetext{
${ }^{5}$ Notice that the absence of ADC in (1), as in Jorgenson's original work, is in fact a special case of linear ADC with $\Pi_{33}=0$. Then, Haavelmo (1960)'s criticism that no optimal rate of investment is defined clearly emerges from the above analysis.

${ }^{6}$ Notice that this form of the technology can be equivalently seen as being characterized by long-run constant returns to scale (Berndt, 1980).
} 
and Tobin's $q$ model is now written as

$$
\Delta K / K=h\left(q^{A}, w, t\right)
$$

where $h=-\rho_{2}^{-1}\left(\right.$.) and $q^{A}$ is the after tax average $q$.

Let us now briefly review the rational flexible accelerator model emphasizing the ADC aspect of it. The specification of the model has three ingredients (see Treadway, 1969):

$$
\begin{aligned}
& \Delta K=\theta^{*}\left(K^{*}-K\right) \\
& \theta^{*}=-1 / 2\left\{r-\left[r^{2}-\frac{4 \Pi_{22}^{*}+r \Pi_{32}^{*}}{\Pi_{33}^{*}}\right]^{1 / 2}\right\} \\
& \Pi_{2}^{*}\left(w, K^{*}, 0, t\right)+r \Pi_{3}^{*}\left(w, K^{*}, 0, t\right) \\
& \quad=g(r+\delta)
\end{aligned}
$$

where (6a) describes the accelerator mechanism, (6b) denotes the optimal speed of adjustment, and (6c) implicitly gives the steady-state level of the capital stock ( $r$ is the firm's cost of capital, asterisks denote evaluation at the steady-state level of capital).

From (6) it can be seen that ADC provide the rationale for the flexible accelerator as the speed of adjustment is optimally endogenously selected. It also emerges that $\Pi_{33}^{*} \neq 0$ so that again the technology must be strictly concave in net investment $\left(\Pi_{33}<0\right)$ for the flexible accelerator to obtain. Hence the same point made for the $q$ model applies here. A condition often imposed in the literature (BFW, 1980; Nadiri and Prucha, 1984; Morrison, 1986) that simplifies the estimation of a nonlinear model such as (6) is the assumption that marginal ADC are zero in the steady-state. This hypothesis is convenient because it implies ADC separability $\Pi_{32}^{*}=0$, makes (6b) simpler, and reduces (6c) to $\mathrm{II}_{2}^{*}()=.g(r+$ $\delta$ ). This expression is just the envelope condition of the traditional Marshallian static equilibrium analysis of the firm. Rejection of ADC separability results in the rejection of this convenient simplification.

The most significant implication of a long-run constant returns technology in the context of flexible accelerator models as given in (6) is that the long-run capital stock is not defined: hence no such model exists under the conditions stated above. This fact can be easily seen from the specification of the profit function (4) that underlies a linear homogeneous technology and it is hardly a surprising result since the steady-state analysis becomes in this case equivalent to the static analysis under constant returns and pricetaking profit maximizing behavior. ${ }^{7}$ This fact holds regardless of $\mathrm{ADC}$ separability. One would therefore conclude that if the technology-cum-ADC were characterized by long-run constant returns, then Tobin's $q$ would be the appropriate model given the above framework and observable average $q$ could be used in lieu of the marginal ratio. Rational flexible accelerator specifications could be used in empirical work only if the underlying behavioral assumption were that of an exogenously given activity level. ${ }^{8}$

\section{The Empirical Model and the Econometric Implementation}

In order to carry out the proposed empirical investigation, it is assumed that the firm is in temporary equilibrium: that is, it optimizes the use of variable inputs conditional on a given stock of capital. The short-run production model is thus represented by a normalized restricted profit function (NRPF hereafter) and by variable factor demand equations, augmented by net investment owing to internal ADC. ${ }^{9}$

A model of this sort belongs to the class that has been termed "second generation dynamics" by Berndt, Morrison and Campbell Watkins

\footnotetext{
${ }^{7}$ When $K=K^{*}$ and $\Delta K=0$ in (4), then $\Pi_{2}^{*}()=.\rho(w, 0, t)$ in (6c). This expression does not depend on $K^{*}$ and therefore there is no target capital stock for the accelerator mechanism in $(6 a)$.

${ }^{8}$ This is the cost minimization framework developed by BFW (1980) and applied also by Nadiri and Prucha (1984), Kokkelenberg (1984), and several others in dynamic factor demand studies.

${ }^{9}$ Several empirical studies have exploited the ADC notion to investigate production and investment activities in a dynamic environment. The $q$ literature usually postulates external ADC depending on either investment or the investment-capital ratio. As pointed out in the previous section, these cases are less empirically convenient for the present purposes. In the flexible accelerator literature, ADC are internal but usually strongly separable. Pindyck and Rotemberg (1983) postulate an external ADC function and test whether such costs depend on gross or on net investment, concluding in favor of the latter. Morrison (1986)'s investigation compares four models with both internal and external ADC depending either on gross or net investment. Internal ADC are favored relative to external ones and, unlike the latter, the former are shown to satisfy the required curvature conditions. ADC depending on gross investment are preferred to the net investment specification. Unfortunately, weak separability is imposed on all models and the internal-net investment ADC model assumes zero marginal ADC.
} 
(1981). Among the alleged drawbacks of such an approach is the inner incompleteness in that it does not specify the time path of adjustment from short- to long-run. This will cause inefficiency in the estimates but will avoid misspecification errors if a flexible accelerator is specified under conditions for which a steady-state capital stock is not defined. Unlike all other "second generation" dynamic models we explicitly introduce ADC, thus recognizing the quasi-fixity of some inputs: a straightforward way to decide if a factor is variable is to test whether ADC for it are zero. Most important, dynamic models of investment based on optimizing behavior are usually derived under the maintained assumption that ADC exhibit a specific pattern. However, the converse is not true: ADC may be present independently of particular solutions to the intertemporal maximization problem. Thus, the drawbacks of the second generation dynamic model to be implemented here turn out to be its strength in this context.

In the empirical investigation we adopt a KLEM (capital, labor, energy, and materials) specification for the technology and regard capital as the only quasi-fixed factor. The true NRPF is approximated by the following quadratic form: ${ }^{10}$

$$
\begin{aligned}
\Pi= & \Pi(w, K, \Delta K, t) \\
= & a_{0}+a_{L} p_{L}+a_{E} p_{E}+a_{M} p_{M}+a_{K} K+a_{t} t \\
& +1 / 2\left(b_{L L} p_{L}^{2}+b_{E E} p_{E}^{2}+b_{M M} p_{M}^{2}\right. \\
& \left.\quad+b_{K K} K^{2}+b_{C C} \Delta K^{2}\right) \\
& +b_{L E} p_{L} p_{E}+b_{L M} p_{L} p_{M}+b_{E M} p_{E} p_{M} \\
& +b_{L K} p_{L} K+b_{E K} p_{E} K \\
& +b_{M K} p_{M} K+b_{L C} p_{L} \Delta K+b_{E C} p_{E} \Delta K \\
& +b_{M C} p_{M} \Delta K+b_{K C} K \Delta K
\end{aligned}
$$

where the input prices are divided by the output deflator and $t$ is a time trend that allows for (linear disembodied) technical change.

Applying Hotelling's lemma to (7), the following demand equations for the variable inputs-

\footnotetext{
${ }^{10}$ A quadratic restricted profit function was first proposed in the ADC context by Berndt, Fuss and Waverman (1977). See Diewert (1986) for a thorough discussion on the properties and advantages of such a flexible functional form.
}

labor, energy and materials-are obtained:

$$
\begin{gathered}
L=-\left(a_{L}+b_{L L} p_{L}+b_{L E} p_{E}+b_{L M} p_{M}\right. \\
\left.+b_{L K} K+b_{L C} \Delta K\right) \\
E=-\left(a_{E}+b_{L E} p_{L}+b_{E E} p_{E}+b_{E M} p_{M}\right. \\
\left.+b_{E K} K+b_{E C} \Delta K\right) \\
M=-\left(a_{M}+b_{L M} p_{L}+b_{E M} p_{E}+b_{M M} p_{M}\right. \\
\left.+b_{M K} K+b_{M C} \Delta K\right) .
\end{gathered}
$$

The quadratic specification was selected because it can accommodate negative values for its arguments, as is required and is sometimes the case with net investment. ${ }^{11}$ The major advantage of the quadratic form is that it satisfies the curvature conditions globally so that the concavity of the NRPF with respect to $\Delta K$ can be statistically tested, as the second partials of such a function are constant.

The system (7)-(10) is estimated and results presented in the next section. It can be seen that it incorporates all the relevant information on ADC needed for the present purposes. In particular, the idea that ADC should cause a marginal output loss amounts to negative marginal profits of net investment. In addition, strict concavity of the ADC technology in net investment implies $b_{C C}<0 .{ }^{12}$ Once it is established that ADC are "well behaved," separability of ADC can be tested by imposing the following sequence of parametric restrictions. Weak separability requires: $b_{L C}=b_{E C}=b_{M C}=0$. Strong ADC separability further requires $b_{K C}=0$. Finally, an easy way of testing for the absence of internal ADC for capital in addition implies $b_{C C}=0 .{ }^{13}$

The technology underlying the empirical system (7)-(10) makes no assumptions about the degree of returns to scale. However, if the technology is linear homogeneous, then a rational flexible accelerator model is an inappropriate description of investment behavior. The major dis-

\footnotetext{
${ }^{11}$ In our sample net investment was negative in 1959.

${ }^{12}$ Notice that marginal ADC here are non-zero even when $\Delta K=0$, which, as was noted before, is a common hypothesis in the empirical literature. In that case, monotonicity and curvature requirements for $\Delta K$ conveniently reduce to the same constant: that is, $b_{C C}$.

${ }^{13}$ We interpret the statistical significance of this parameter at the end of the described test sequence as supporting the idea of costs associated with changes in the level of the capital stock. It is worth pointing out that this inference is not foolproof, in that investment might affect variable profits for reasons other than $\mathrm{ADC}$.
} 
advantage of the quadratic functional form is that linear homogeneity restrictions cannot be imposed parametrically on (7) (see Diewert, 1986, p. 95). Under such circumstances the empirical model becomes

$$
\begin{aligned}
\Pi / K= & \rho(w, \Delta K / K, t) \\
= & a_{0}+a_{L} p_{L}+a_{E} p_{E}+a_{M} p_{M}+a_{t} t \\
& +1 / 2\left[b_{L L} p_{L}^{2}+b_{E E} p_{E}^{2}+b_{M M} p_{M}^{2}\right. \\
& \left.+b_{C C}(\Delta K / K)^{2}\right] \\
& +b_{L E} p_{L} p_{E}+b_{L M} p_{L} p_{M}+b_{E M} p_{E} p_{M} \\
& +b_{L C} p_{L}(\Delta K / K)+b_{E C} p_{E}(\Delta K / K) \\
& +b_{M C} p_{M}(\Delta K / K) \\
L / K= & -\left[a_{L}+b_{L L} p_{L}+b_{L E} p_{E}+b_{L M} p_{M}\right. \\
& \left.+b_{L C}(\Delta K / K)\right] \\
E / K= & -\left[a_{E}+b_{L E} p_{L}+b_{E E} p_{E}+b_{E M} p_{M}\right. \\
& \left.+b_{E C}(\Delta K / K)\right] \\
M / K= & -\left[a_{M}+b_{L M} p_{L}\right. \\
& +b_{E M} p_{E}+b_{M M} p_{M}
\end{aligned}
$$

As before, upon estimation of (11)-(14), one can again assess the monotonicity and curvature properties of the variable profit function imposed by ADC and undertake the aforementioned sequence of ADC separability test.

As an illustration, the two models were estimated using data for the U.S. total manufacturing sector over the 1947-71 period. The data set employed is very popular in the applied production literature and has been developed by Berndt and Wood (1975). ${ }^{14}$

Classical additive disturbances were appended and symmetry of the parameters across equations imposed at the outset. Correction for first-order autocorrelation of the error terms was made by writing the models in quasi-differenced form and simultaneously estimating the autoregressive coefficients along with the structural parameters (Kmenta and Gilbert, 1970). While prices were taken to be exogenous, net investment and capital stock were recognized to be decision variables of the dynamic optimization problem faced by the

\footnotetext{
${ }^{14}$ The description and tabulation of the actual numbers employed here can be found in Galeotti (1986). The data were expressed as deviations from their 1958 values.
}

firm. Thus, they are regarded as endogenous variables correlated with the disturbances. To avoid the ensuing simultaneity bias, an instrumental variable procedure was undertaken. ${ }^{15}$ Once this was done, the iterated Zellner efficient method (IZEF) was employed.

The two models were both independently estimated. This is because in the present context the quadratic technologies under the linear homogeneity and the non-homogeneity hypotheses represent two nonnested regression systems of equations. In both cases the ADC structure was then subject to the sequence of nested separability tests mentioned above using a standard likelihood ratio criterion. Statistically discriminating between the linear homogeneous and the nonhomogeneous specifications is more problematic. The difficulty arises from the fact that nonnested tests proposed in the literature cannot be carried out, as the dependent variables are not the same for the two models. ${ }^{16}$ Nevertheless, notice that in a profit function framework long-run constant returns obtain if $\partial^{2} \Pi / \partial K^{2}=0$ (when $\Delta K=0$ ). In the quadratic specification this derivative is given by the parameter $b_{K K}$; hence, when estimating the nonhomogeneous system (7)-(10), if we find that $b_{K K}$ is not statistically different from zero, we conclude that the alternative model (11)-(14) is more appropriate for our data, because there is evidence of long-run constant returns to scale.

\section{Empirical Results}

Table 1 reports the estimated coefficients of the linear homogeneous and nonhomogeneous technology models incorporating a nonseparable ADC structure. Both models fit the data quite well and the individual $R$-squares are high; in addition, both models meet all the regularity con-

\footnotetext{
${ }^{15}$ The first stage had $\Delta K, K$, and $\Delta K / K$, respectively regressed against a set of instruments which included current, once, and twice lagged real input prices (including the price of capital), a time trend and its square.

${ }^{16}$ Recently nonnested tests for models where the dependent variables are subject to a known data transformation have been proposed by MacKinnon, White and Davidson (1983) and by Bera and McAleer (1985) in a single equation context. Unfortunately, as explained in the first article (p. 56), tests of this sort cannot be expected to have any optimality properties; in addition, in the absence of suitable adjustments, nonnested tests tend to overreject the null hypothesis in small samples (Godfrey and Pesaran, 1983).
} 
Table 1.-Parameter Estimates of the Nonseparable Adjustment Cost Models, U.S. MANUfacturing, 1950-1971

\begin{tabular}{|c|c|c|}
\hline Parameters & $\begin{array}{l}\text { Non-homogeneous } \\
\text { Technology Model }\end{array}$ & $\begin{array}{c}\text { Linear Homogeneous } \\
\text { Technology Model }\end{array}$ \\
\hline$a_{0}$ & $50.99 \quad(3.407)$ & $(0.028)$ \\
\hline$a_{L}$ & $-34.60 \quad(1.394)$ & $-0.42 \quad(0.009)$ \\
\hline$a_{E}$ & $-15.69 \quad(0.092)$ & $-0.19 \quad(0.002)$ \\
\hline$a_{M}$ & $-222.15 \quad(4.858)$ & $(0.058)$ \\
\hline$a_{K}$ & $1.44 \quad(0.232)$ & - \\
\hline$b_{L L}$ & $6.95 \quad(1.970)$ & $(0.012)$ \\
\hline$b_{E E}^{L L}$ & $5.04 \quad(2.037)$ & $(0.042)$ \\
\hline$b_{M M}^{C E}$ & $655.31(86.18)$ & $(0.768)$ \\
\hline$b_{K K}$ & $-0.002(0.005)$ & - \\
\hline$b_{C C}$ & $-0.58 \quad(0.165)$ & $-52.43 \quad(22.222)$ \\
\hline$b_{L E}$ & $-4.90 \quad(0.663)$ & $-0.003 \quad(0.004)$ \\
\hline$b_{L M}$ & $25.24 \quad(8.919)$ & $-0.075 \quad(0.074)$ \\
\hline$b_{E M}$ & $-17.76 \quad(5.254)$ & $0.074 \quad(0.093)$ \\
\hline$b_{L K}$ & $-0.35 \quad(0.057)$ & - \\
\hline$b_{E K}$ & $-0.07 \quad(0.018)$ & - \\
\hline$b_{M K}$ & $-3.85 \quad(0.331)$ & - \\
\hline$b_{L C}$ & $-0.061(0.113)$ & $(0.136)$ \\
\hline$b_{E C}$ & $-0.077(0.034)$ & $(0.077)$ \\
\hline$b_{M C}$ & $-2.56 \quad(0.871)$ & $(0.998)$ \\
\hline$b_{K C}$ & $0.022(0.013)$ & \\
\hline$a_{T}$ & $1.62 \quad(0.469)$ & $0.034 \quad(0.003)$ \\
\hline$\rho_{\Pi}$ & $0.45 \quad(0.096)$ & $(0.128)$ \\
\hline$\rho_{L}$ & $0.64 \quad(0.097)$ & $(0.104)$ \\
\hline$\rho_{E}$ & $-0.15 \quad(0.116)$ & $(0.148)$ \\
\hline$\rho_{M}$ & $0.23 \quad(0.095)$ & $(0.108)$ \\
\hline $\ln L$ & -145.832 & 230.569 \\
\hline$R$-squ & 0.9815 & 0.9834 \\
\hline$R$-square $(L)$ & 0.9973 & 0.9973 \\
\hline$R$-square $(E)$ & 0.9995 & 0.9991 \\
\hline$R$-square $(M)$ & 0.9963 & 0.9961 \\
\hline
\end{tabular}

Note: Asymptotic standard errors are in parentheses. The $R$-square values are computed as the squares of the correlation coefficients for the actual and fitted values of the dependent variables of the profit $(\Pi)$, labor $(L)$, energy $(E)$, and materials $(M)$ demand equations.

ditions required for a well-behaved NRPF-cumADC.

For each specification, tests of ADC separability are nested within each other and sequential. ${ }^{17}$ Table 2 summarizes the findings. In the linear homogeneous technology case, ADC separability with respect to the levels of all inputs is rejected at the 5\% level. Complete absence of internal ADC is accordingly rejected. It appears that adding to the existing capacity does cause major technological effects on the way production is organized: installation is not separate from production activity. The conclusion to be drawn is that empirical studies postulating separable ADC

\footnotetext{
${ }^{17}$ The overall significance level was set at $10 \%$ : this amount was evenly distributed so that each hypothesis was treated symmetrically. The estimation results for the intermediate models are reported in Galeotti (1986).
}

structures suffer from specification errors. ${ }^{18}$

Turning to the nonhomogeneous technology model, the results of the test appear to reject all kinds of ADC separability, consistently with the linear homogeneous case. The widely held assumption of zero marginal ADC is not supported by the data and it follows that empirically valid flexible accelerator models are necessarily more complicated in this respect than the flexible accelerator models presented in the literature. From the results of the nonhomogeneous specification of table 1 it also emerges that the parameter $b_{K K}$ is not statistically different from zero. ${ }^{19}$ This fact supports the hypothesis that a long-run constant returns technology better describes the data and is also consistent with findings of previous empirical work using the same data set (Berndt and Christensen, 1973, and Berndt and Wood, 1975). ${ }^{20}$

The last requirement to be considered, as far as ADC are concerned, are the curvature and the monotonicity conditions. In terms of the first aspect, the negative and strongly significant parameter $b_{C C}$ implies the strict concavity of ADC and supports, at this level of aggregation, the existence of optimal decision rules and of finite smooth investment relationships. Notice that this result is obtained without imposing that the firm is actually in a dynamic equilibrium position. This confirms the inconsistency of Jorgensonian investment equations where ADC were absent.

The monotonicity condition depeids not only on the estimated parameters but also on the right-hand side variables of the system. Therefore, it is not invariant to the sample and the behavior of the NRPF has to be checked locally at each observation. To this purpose, no published work has presented evidence about the negative impact that ADC have on current production levels. The empirical results presented in table 3 are consistent with this theoretical expec-

\footnotetext{
${ }^{18}$ Kokkelenberg (1984) imposes no restrictions on internal ADC in his analysis. He finds evidence supporting nonseparability but stresses that no statistical test is provided. The findings here confirm his conclusion.

${ }^{19}$ This was also the case for all intermediate ADC specifications: see Galeotti (1986).

${ }^{20}$ As anticipated before, nonested tests did not yield an unambiguous outcome. Using the procedure of Bera and McAleer (1985), we obtained values of the likelihood ratio test equal to 29.98 and to 27.86 with the linear homogeneous and the nonhomogeneous specifications, respectively, serving as the null hypothesis. With four degrees of freedom both specifications rejected each other.
} 
THE REVIEW OF ECONOMICS AND STATISTICS

\begin{tabular}{|c|c|c|c|}
\hline \multicolumn{4}{|c|}{ Panel A: Linear Homogeneous Technology Model } \\
\hline Restrictions & $\begin{array}{l}\text { Likelihood } \\
\text { Ratio }\end{array}$ & $\begin{array}{l}\text { Number of } \\
\text { Restrictions }\end{array}$ & $\begin{array}{c}\text { Critical } \chi^{2} \\
\text { Value } \alpha=5 \%\end{array}$ \\
\hline $\begin{array}{l}\text { Separability } \\
b_{L C}=b_{E C}=b_{M C}=0 \\
\text { No Internal }\end{array}$ & 9.204 & 3 & 7.8 \\
\hline $\begin{array}{l}\text { Adjustment Costs } \\
b_{C C}=0\end{array}$ & 11.742 & 1 & 3.8 \\
\hline \multicolumn{4}{|c|}{ Panel B: Nonhomogeneous Technology Model } \\
\hline Restrictions & $\begin{array}{l}\text { Likelihood } \\
\text { Ratio }\end{array}$ & $\begin{array}{l}\text { Number of } \\
\text { Restrictions }\end{array}$ & $\begin{array}{c}\text { Critical } \chi^{2} \\
\text { Value } \alpha=3.7 \%\end{array}$ \\
\hline $\begin{array}{l}\text { Weak Separability } \\
\qquad b_{L C}=b_{E C}=b_{M C}=0\end{array}$ & 11.124 & 3 & 8.6 \\
\hline $\begin{array}{l}\text { Strong Separability } \\
b_{K C}=0 \\
\text { No Internal }\end{array}$ & 1.752 & 1 & 4.4 \\
\hline $\begin{array}{l}\text { Adjustment Costs } \\
b_{C C}=0\end{array}$ & 13.964 & 1 & 4.4 \\
\hline
\end{tabular}

tation at all sample points, which, in turn, would insure that the underlying structural model of investment satisfies theoretical expectations. ${ }^{21}$

\section{Adjustment Cost Indicators and Empirical Investment Equations}

From the empirical results presented in the previous section it appears that the model derived under the assumption of a long-run constant returns technology provides a better description of the data. ${ }^{22}$ Taken at face value, this fact implies that a (rational) flexible accelerator model is ill-defined when the underlying behavioral assumption is that of a price-taking profit maximizing firm. ${ }^{23}$ In terms of the competing specification, it emerges that empirical $q$ equations ought to be amended to include, besides Tobin's $q$, relative factor prices as separate regressors because of the nonseparable nature of internal ADC. On the other hand, the evidence supports the result that average and marginal $q$

\footnotetext{
${ }^{21}$ The nonhomogeneous model satisfies this regularity condition at each data point as well.

${ }^{2}$ Hence, the following considerations will be based on the linear homogeneous model.

${ }^{23}$ Obviously, such a model is correci for cost minimizing firms taking output as given.
}

Table 3.-Marginal Profitability of Net INVESTMENT (MARginal ADC), U.S. MANUfACTURING, 1950-1971

\begin{tabular}{lc}
\hline \hline Year & Marginal Adjustment Costs $(\partial \Pi / \partial \Delta K)$ \\
\hline 1950 & -4.035 \\
1951 & -1.495 \\
1952 & -2.093 \\
1953 & -1.646 \\
1954 & -1.536 \\
1955 & -1.287 \\
1956 & -2.524 \\
1957 & -2.089 \\
1958 & -0.181 \\
1959 & -0.280 \\
1960 & -0.340 \\
1961 & -0.117 \\
1962 & -0.431 \\
1963 & -0.794 \\
1964 & -1.595 \\
1965 & -2.921 \\
1966 & -3.854 \\
1967 & -3.208 \\
1968 & -2.184 \\
1969 & -1.983 \\
1970 & -1.069 \\
1971 & -0.062 \\
\hline
\end{tabular}

Note: Computed from the linear homogeneous technology specification with nonseparable adjustment costs. Marginal adjustment costs given by $\partial \Pi / \partial \Delta K=b_{L C} p_{L}+b_{E C} p_{E}+b_{M C} p_{M}+b_{C C}(\Delta K / K)$. 
Table 4.-Adjustment Cost Indicators

\begin{tabular}{ll}
\hline \hline 1. Total ADC & 4.390 \\
2. Marginal ADC & 1.570 \\
3. Total ADC/Variable Profits & 0.081 \\
4. Total ADC/Gross Output & 0.010 \\
5. Marginal ADC/Variable Profits & 0.029 \\
6. Incidence of ADC expenditures & \\
$\quad$ on total investment expenditures & \\
per dollar of investment & 0.600 \\
\hline
\end{tabular}

Note: Indicators based on the estimated coefficients of the linear homogeneous technology model with nonseparable adjustment costs. Average values in 1958 billion dollars. Row 1 is computed as $\mathrm{ADC}=(\Delta K / K)\left(b_{L C} p_{L}+\right.$ $\left.b_{E C} p_{E}+b_{M C} p_{M}+0.5^{*} b_{C C}(\Delta K / K)\right)$. Row 2 is computed as in table 3 . Row 6 is computed as $M A D C /\left(p^{I}+M A D C\right)$ where $p^{I}$ is the market price of investment.

are equal, so that the latter can be rightfully used in lieu of the theoretically relevant but unobservable marginal ratio. It should be stressed that this information has been generated by a model which makes no assumptions about the evolution of the firm's quasi-fixed input over time: no optimality rule has been imposed. Nonetheless, if one is willing to assume that the stock of capital evolves optimally over time, then it follows that the marginal "profitability" of investment is the inverse of the coefficient of $q$ in the estimated investment equations. The estimates of the (mean) inverse of this coefficient and the implied estimates of the elasticity of investment with respect to $q$ are computed from the figures shown in table 3 . The mean value of the elasticity is equal to 0.36 . This estimate is in line with those reported by other researchers: for instance, the elasticity implied by Hayashi (1982)'s results is 0.29 and that implied by Blanchard and Wyplosz (1981) is 0.43. In particular, the problem of low elasticities of investment relative to $q$ emerges here as well, suggesting that the neoclassical interpretation of Tobin's $q$ theory may be inadequate: that is, it may be inappropriate to regard investment behavior as being solely explained by the value of $q$. This fact seems to be true independently of the use of marginal rather than average $q .^{24}$

We conclude this section with a look at some ADC indicators in table 4. The magnitude of overall internal ADC in capital has been on average equal to 4 billion dollars (at 1958 prices) over

\footnotetext{
${ }^{24}$ Thus our findings are in line with Abel and Blanchard's (1986) conclusion that there is "little support for the view that the low explanatory power of average $q$ is due to the fact that average $q$ is simply a poor proxy for the theoretically more appealing marginal $q$ " (p. 250).
}

the $1950-71$ period. The impact on variable profits of a unit ADC can be quantified in 1.5 billions on average. The ratio of total ADC to variable profits and to output is quite small and is estimated to be equal to 0.08 and 0.01 , respectively. The value of $\mathrm{ADC}$ at the margin relative to the ex-post return to capital stock is about $0.03 .{ }^{25}$ From the last row of the table it finally emerges that internal ADC represent a substantial percentage of the unit cost of investment, i.e., about $60 \%$. This gives a clear idea of the consequences of neglecting the ADC component in applied work.

\section{Conclusions}

In this paper estimation results are presented for an aggregate short-run production model incorporating a rich structure of ADC in the capital input, under the assumption of competitive profit maximizing behavior. The consequences of the structure of the ADC technology for theoretical and applied investment analysis have been shown to be very relevant.

The findings can be summarized as follows. (1) In the aggregate, ADC appear to have the impact predicted by the theory: they negatively affect current production and rise rapidly as the rate of investment increases. (2) Installation of new capital goods is not a separate activity relative to current production within the firm: ADC are nonseparable and there is evidence that the levels of both variable and quasi-fixed inputs affect marginal ADC. (3) The ADC technology is best described by long-run constant returns to scale. The $q$ model appears to be the appropriate specification for this situation and average and marginal $q$ are consequently equal.

The empirical model adopted here describes the firm's short-run behavior. The most important result of the analysis has been that of documenting the particular pattern attributed to ADC by dynamic models of investment and dynamic factor demands without making any explicit assumption about the optimal evolution of quasi-fixed inputs over time.

\footnotetext{
${ }^{25}$ See row 5 . Since by definition variable profits are the residual left after deducting current expenses from revenues, then they represent the ex-post return to capital. Given this interpretation, the figure can be compared to the "percentage total ADC" computed by Pindyck and Rotemberg (1983) which, for aggregate capital stock, is 0.056 .
} 
The problem with ADC is of course that they are not directly observable. Here, inference about $\mathrm{ADC}$ has been made without resorting to the estimation of investment equations, as has been common practice. Nevertheless, given the reduced form nature of the treatment of $\mathrm{ADC}$ in this paper (because direct observations on ADC are not available), the empirical evidence presented is still indirect.

\section{REFERENCES}

Abel, Andrew, Investment and the Value of Capital (New York: Garland Press, 1979).

Abel, Andrew, and Olivier Blanchard, "The Present Value of Profits and Cyclical Movements in Investment," Econometrica 54 (Mar. 1986), 249-273.

Bera, Anil, and Michael McAleer, "Nested and Non-nested Procedures for Testing Linear and Log-linear Regression Models," BEBR Working Paper no. 1130 (Mar. 1985).

Berndt, Ernst, "Energy Price Increases and the Productivity Slowdown in United States Manufacturing," in The Decline of Productivity Growth, Federal Reserve Bank of Boston Conference Series no. 22 (June 1980), 60-89.

Berndt, Ernst, and Laurits Christensen, "The Translog Production Function and the Substitution of Equipment, Structures and Labor in U.S. Manufacturing 19291968," Journal of Econometrics 1 (Mar. 1973), 81-114.

Berndt, Ernst, Melvyn Fuss, and'Leonard Waverman, $D y$ namic Models of the Industrial Demand for Energy (Palo Alto: Electric Power Research Institute, 1977), Interim Report EPRI EA-580.

, Dynamic Adjustment Models of Industrial Energy Demand: Empirical Analysis for U.S. Manufacturing, 1947-1974 (Palo Alto: Electric Power Research Institute, 1980), Final Report EA-1613.

Berndt, Ernst, Catherine Morrison and G. Campbell Watkins, "Dynamic Models of Energy Demand: An Assessment and Comparison," in Ernst Berndt and B. Field (eds.), Modeling and Measuring Natural Resource Substitution (Cambridge: MIT Press, 1981), 259-289.

Berndt, Ernst, and David Wood, "Technology, Prices, and the Derived Demand for Energy," this REVIEw 57 (Aug. 1975), 259-268.

Blanchard, Olivier, and Charles Wyplosz, "An Empirical Structural Model of Aggregate Demand," Journal of Monetary Economics 7 (Jan. 1981), 1-28.

Chirinko, Robert, "Tobin's $Q$ and Financial Policy," Journal of Monetary Economics 19 (Jan. 1987), 69-87.

Diewert, Walter E., The Measurement of Economic Benefits of Infrastructure Services (Berlin: Springer-Verlag, 1986).

Eisner, Robert, and Robert Strotz, "Determinants of Investment Behavior," in Commission on Money and Credit, Impact of Monetary Policy (Englewood Cliffs: PrenticeHall, 1963).
Galeotti, Marzio, "Essays in Applied Investment Theory," unpublished Ph.D. dissertation, New York University (1986).

Godfrey, Leslie, and M. Hashem Pesaran, "Tests of Nonnested Regression Models: Small Sample Adjustments and Monte Carlo Evidence," Journal of Econometrics 21 (Jan. 1983), 133-154.

Haavelmo, Trigve, A Study in the Theory of Investment (Chicago: University of Chicago Press, 1960).

Hayashi, Fumio, "Tobin's Marginal $q$ and Average $q$ : A Neoclassical Interpretation," Econometrica 50 (Jan. 1982), 213-224. , "Corporate Finance Side of the $Q$ Theory of Investment," Journal of Public Economics 27 (Aug. 1985), 261-280.

Kmenta, Jan, and R. Gilbert, "Estimation of Seemingly Unrelated Regressions with Autoregressive Disturbances," Journal of the American Statistical Association 65 (Mar. 1970), 186-197.

Kokkelenberg, Edward, "The Specification and Estimation of Interrelated Factor Demands under Uncertainty," Journal of Economic Dynamics and Control 7 (Sept. 1984), 181-207.

Lau, Lawrence, "Applications of Profit Functions," in Melvyn Fuss and Daniel McFadden (eds.), Production Economics: A Dual Approach to Theory and Applications, vol. II (Amsterdam: North-Holland, 1978), 133-216.

Locke Anderson, Walter, "Comments to D. Jorgenson's Investment and Production: A Review," in Michael Intriligator and David Kendrick (eds.), Frontiers of Quantitative Economics, vol. II (Amsterdam: North-Holland, 1974), 366-368.

MacKinnon, James, Halbert White, and Russell Davidson, "Tests for Model Specification in the Presence of Alternative Hypotheses: Some Further Results," Journal of Econometrics 21 (Jan. 1983), 53-70.

Morrison, Catherine, "Dynamic Factor Demands, Market Power, and the Shape of the Adjustment Cost Function," mimeo (1986), forthcoming in Ernst Berndt and M. Ishaq Nadiri (eds.), Temporary Equilibrium and Costs of Adjustment.

Nadiri, M. Ishaq, and Ingmar Prucha, "Dynamic Factor Demand Functions with Nonstatic Expectations and Adjustment Costs: The Case of the U.S. Bell System," mimeo (1984), forthcoming in Ernst Berndt and M. Ishaq Nadiri (eds.), Temporary Equilibrium and Costs of Adjustment.

Pindyck, Robert, and Julio Rotemberg, "Dynamic Factor Demands under Rational Expectations," Scandinavian Journal of Economics 85 (July 1983), 223-238.

Rothschild, Michael, "On the Cost of Adjustment," Quarterly Journal of Economics 85 (Nov. 1971), 605-622.

Soderstrom, Hal, "Production and Investment under Costs of Adjustment: A Survey," Zeitschrift fur Nationalokonomie 36 (3) (1976), 369-388.

Treadway, Arthur, "On Rational Entrepreneurial Behaviour and the Demand for Investment," Review of Economic Studies 36 (Apr. 1969), 227-239. 